\title{
'||||||||||||||||||||||||||||||||||||||||||||||||||||||||||||||||.
}

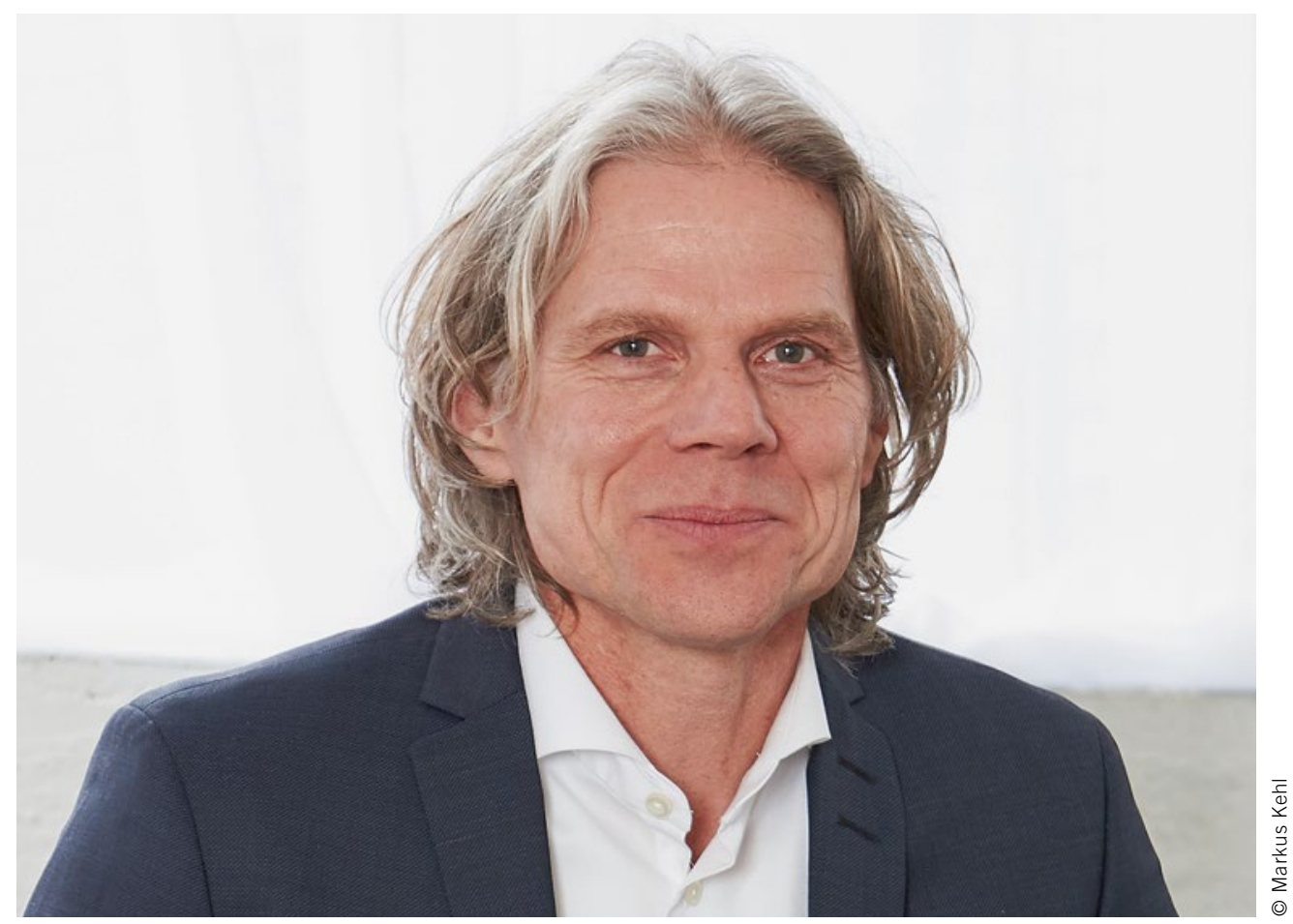

Thomas Korn

Founder and CEO

of the Keyou $\mathrm{GmbH}$

in Unterschleißheim

(Germany)

\section{The Hydrogen Engine is on its Way}

Writing about the evolution of the internal combustion engine against the backdrop of the coronavirus pandemic is not at all easy. Or is this precisely the moment when we should be talking about the post-coronavirus era? Should we restart the discussions about the climate crisis, the energy transition and alternative powertrains? This seems to be particularly relevant at a time when many people are politicizing the pandemic and calling for a relaxation of the strict $\mathrm{CO}_{2}$ targets.

A wide range of different options are being considered to enable the transport sector to meet its global $\mathrm{CO}_{2}$ targets, including electric motors, hybrid drives, hydrogen technologies and synthetic fuels. The challenge lies in developing technologies that can be produced quickly and easily on an industrial scale and that can be successfully sold because of their high level of value for customers. As a large proportion of the vehicles currently being produced still have combustion engines, the engine itself must become an essential means of combating the climate crisis. This has been recognized by the EU, which classifies vehicles with combustion engines as zero-emission vehicles if their emission levels are below $1 \mathrm{~g} \mathrm{CO}_{2} / \mathrm{kWh}$. This is possible. By using modern hydrogen combustion engines.

There are several reasons for choosing this type of powertrain, in particular in the commercial vehicle sector. The latest hydrogen engines have a range and a refueling time similar to those of conventional engines. In addition, they are absolutely suitable for everyday use - an important selling point for end customers. Another consideration is the low $\mathrm{CO}_{2}$ footprint over the entire life cycle of the engines. Nowadays many consumers not only prefer to buy environmentally friendly products; they also increasingly expect them to be climate-neutral.

There are also strong arguments in favor of the hydrogen engine for engine and vehicle manufacturers. They and their suppliers can make use of existing production infrastructures and skilled employees. This helps to keep the necessary investments to a minimum. In addition, the zero-emission hydrogen engine will enable manufacturers to meet the strict fleet $\mathrm{CO}_{2}$ targets and avoid financial penalties. It is a genuinely useful merger of technology, ecology and economics.

Skeptics continue to argue that the hydrogen engine is not efficient and to claim that its consumption levels are too high, but is that really true? In city buses and trucks a cost-effective Port Fuel Injection (PFI) engine in a P2 hybrid configuration can use less fuel than a fuel cell vehicle. In long-haul transport with high propotions of full load operation, a robust direct injection hydrogen engine with a high power density can have lower fuel consumption than an efficient diesel engine and provide the greatest value for customers. This is not what poor efficiency looks like.

The question is not whether the hydrogen engine is coming, but when. 